\title{
Prevalence and Influencing Factors of Metabolic Syndrome among Adults in China from 2015 to 2017
}

\author{
Fan Yao ${ }^{1}$, Yacong Bo ${ }^{2}$, Liyun Zhao ${ }^{1}$, Yaru Li ${ }^{3}$, Lahong Ju ${ }^{1}$, Hongyun Fang ${ }^{1}$, Wei Piao ${ }^{1}$, Dongmei Yu ${ }^{1, *}$ \\ and Xiangqian Lao ${ }^{2}$
}

check for updates

Citation: Yao, F.; Bo, Y.; Zhao, L.; Li, Y.; Ju, L.; Fang, H.; Piao, W.; Yu, D.; Lao, X. Prevalence and Influencing Factors of Metabolic Syndrome among Adults in China from 2015 to 2017. Nutrients 2021, 13, 4475. https://doi.org/10.3390/nu13124475

Academic Editor: Alessandro Sartorio

Received: 25 October 2021

Accepted: 10 December 2021

Published: 15 December 2021

Publisher's Note: MDPI stays neutral with regard to jurisdictional claims in published maps and institutional affiliations.

Copyright: (c) 2021 by the authors. Licensee MDPI, Basel, Switzerland. This article is an open access article distributed under the terms and conditions of the Creative Commons Attribution (CC BY) license (https:// creativecommons.org/licenses/by/ $4.0 /)$.
1 Key Laboratory of Trace Element Nutrition of National Health Commission, National Institute for Nutrition and Health, Chinese Center for Disease Control and Prevention, Beijing 100050, China; yao_f@foxmail.com (F.Y.); zhaoly@ninh.chinacdc.cn (L.Z.); julh@ninh.chinacdc.cn (L.J.); fanghy@ninh.chinacdc.cn (H.F.); piaowei@ninh.chinacdc.cn (W.P.)

2 Jockey Club School of Public Health and Primary Care, The Chinese University of Hong Kong, Hong Kong 999077, China; boyacong777@gmail.com (Y.B.); xqlao@cuhk.edu.hk (X.L.)

3 Beijing Friendship Hospital, Beijing 100050, China; liyaru0225@126.com

* Correspondence: yudm@ninh.chinacdc.cn

\begin{abstract}
The prevalence and influencing factors of metabolic syndrome (MetS) in Chinese residents aged 20 or older were investigated. The data were collected from China Nutrition and Health Surveillance (2015-2017), which used a stratified, multistage, random sampling method. A total of 130,018 residents aged 20 years or older from 31 provinces were included in this study. The National Cholesterol Education Programme Adult Treatment Panel III (NCEP ATP III) criteria were used to define MetS. The standardised prevalence of high waist circumference, high blood pressure and low high-density lipoprotein cholesterol were $40.8 \%, 49.4 \%$ and $41.1 \%$, respectively. The following factors were associated with a higher prevalence of MetS: female [odds ratio $(\mathrm{OR})=1.773$, $95 \% \mathrm{CI}=1.709-1.840]$; older age $(\mathrm{OR}=1.037,95 \% \mathrm{CI}=1.036-1.039)$; living in north China $(\mathrm{OR}=1.087$, $95 \% \mathrm{CI}=1.058-1.117)$; high body mass index (OR = 1.402, 95\% CI = 1.395-1.408); higher income [OR (95\% CI): 1.044 (1.007-1.083), 1.083 (1.044-1.124) and 1.123 (1.078-1.170) for moderate, high, and very high income, respectively]; family history of hypertension (OR $=1.237,95 \% \mathrm{CI}=1.203-1.273$ ); family history of diabetes $(\mathrm{OR}=1.491,95 \% \mathrm{CI}=1.426-1.558)$ and current smoking status $(\mathrm{OR}=1.143$, $95 \% \mathrm{CI}=1.098-1.191)$. Living in the countryside $(\mathrm{OR}=0.960,95 \% \mathrm{CI}=0.932-0.988)$, moderate alcohol consumption $(\mathrm{OR}=0.917,95 \% \mathrm{CI}=0.889-0.946)$ and being physically active $(\mathrm{OR}=0.887$, $95 \% \mathrm{CI}=0.862-0.913)$ were associated with a lower prevalence of MetS. The prevalence of MetS among residents aged 20 years or older in China is increasing, especially among women, people aged 45 years or older and urban residents. Preventive efforts, such as quitting smoking and engaging in physical activity, are recommended to reduce the risk of MetS.
\end{abstract}

Keywords: metabolic syndrome; adults; prevalence; influencing factors

\section{Introduction}

Metabolic syndrome (MetS) refers to a set of combined cardiovascular risk factors that, together, constitute cardiovascular risk beyond the sum of the individual components. The main components of MetS are abdominal obesity, insulin resistance, increased blood pressure and dyslipidaemia [1]. With economic development and changes in lifestyle, the prevalence of MetS is increasing worldwide [2,3] and has become a public health issue owing to its serious effect on human health. In 2001, a nationally representative sample survey conducted in 31 provinces and cities in China found that the standardised prevalence of MetS was 13.7\% (men 9.8\%, women 17.8\%) [4]. In 2010-2012, the standardised prevalence of MetS was found to have increased to $24.2 \%$ (men 24.6\%, women 23.8\%) [5]. These data indicate the urgent need for the prevention and control of MetS. Based on 
data from China Nutrition and Health Surveillance (2015-2017), this study evaluated the prevalence and influencing factors of MetS among Chinese residents aged 20 years or older.

\section{Materials and Methods}

\subsection{Data Source}

The data were derived from China Nutrition and Health Surveillance (2015-2017), which adopted a stratified, multistage, random sampling method to recruit representative participants from 31 provinces/municipalities/autonomous regions of China. Detailed information about this survey is given in our previous report [6]. The protocol for the current study was approved by the Ethics Committee of the National Institute for Nutrition and Health, and the Chinese Centre for Disease Control and Prevention (approval numbers: 201519-A and 201614), and all of the participants signed an informed consent form prior to joining the study. A total of 130,018 participants aged 20 years or older were included in the analysis.

\subsection{Data Collection}

China Nutrition and Health Surveillance (2015-2017) collected information using the four following parts: a questionnaire survey, a physical examination, a dietary evaluation and a laboratory test.

\subsubsection{Questionnaire Survey}

A face-to-face questionnaire was used to collected family and personal information, including information on lifestyle factors, health status and physical activity.

\subsubsection{Physical Examination}

Height, weight, waist circumference and blood pressure were measured by trained investigators based on standard methods using a TZG height and sitting height meter, a TANITA HD-390 electronic weighing scale, a waist circumference ruler and an Omron HBP1300 electronic sphygmomanometer. These measurements were accurate to $0.1 \mathrm{~cm}$, $0.1 \mathrm{~kg}, 0.1 \mathrm{~cm}$ and $1 \mathrm{mmHg}$, respectively.

\subsubsection{Dietary Evaluation}

The food frequency questionnaire was used to capture and evaluate the dietary structure and dietary habits of participants over the past year. Specifically, information was collected regarding the consumption of vegetables, fruits and red meat items.

\subsubsection{Laboratory Tests}

An overnight fasting blood sample was collected from each participant to measure blood biochemical indexes and nutritional status parameters.

\subsection{Quality Control}

To ensure quality, the National Project Working Group devised a quality control plan and supervised its implementation. This ensured that there were unified programmes, manuals and questionnaires; unified training and assessment; unified equipment and reagents; and unified data entry and data cleaning across the study sites.

\subsection{Definition of MetS}

MetS was defined according to the National Cholesterol Education Programme-Adult Treatment Panel III (NCEP-ATP III) [7] as having three or more of the following factors: (1) a waist circumference of $\geq 90 \mathrm{~cm}$ for men and $\geq 80 \mathrm{~cm}$ for women; (2) a systolic blood pressure of $\geq 130 \mathrm{mmHg}$ or a diastolic blood pressure of $\geq 85 \mathrm{mmHg}$ or receiving anti-hypertension treatment; (3) a fasting triglyceride level of $\geq 1.7 \mathrm{mmol} / \mathrm{L}$ or receiving corresponding treatment; (4) a high-density lipoprotein cholesterol (HDL-C) level of $<1.03 \mathrm{mmol} / \mathrm{L}$ for men and $<1.30 \mathrm{mmol} / \mathrm{L}$ for women or receiving corresponding treatment; (5) a fasting plasma 
glucose (FPG) level of $\geq 5.6 \mathrm{mmol} / \mathrm{L}$ or receiving anti-diabetes treatment or reporting previously physician-diagnosed diabetes.

\subsection{Covariates}

A wide range of potential confounders were accounted for: (1) body mass index (BMI) was categorised as normal $\left(18.5 \leq\right.$ to $\left.<24 \mathrm{~kg} / \mathrm{m}^{2}\right)$, overweight $\left(24 \leq\right.$ to $\left.<28 \mathrm{~kg} / \mathrm{m}^{2}\right)$ or obese $\left(\geq 28 \mathrm{~kg} / \mathrm{m}^{2}\right)$; (2) education level was categorised as low (primary school or below), moderate (junior school) or high (high school or above); (3) according to the income quartile, income was categorised as low, moderate, high or very high; (4) family history of hypertension (or diabetes) was defined as one or more of a grandfather, grandmother, father, mother or brother/sister suffering from hypertension (or diabetes); (5) smoking was categorised as never smoked, formerly smoked or currently smoke; (6) alcohol consumption was categorised as never consumed, moderately consume (men consume less than $25 \mathrm{~g}$ of alcohol and women less than $15 \mathrm{~g}$ of alcohol per day) or excessively consume (men consume more than $25 \mathrm{~g}$ and women more than $15 \mathrm{~g}$ per day); (7) physical activity was defined as inactive if, within one week, the total time of moderate-intensity activity was less than $150 \mathrm{~min}$, or high-intensity activity was less than $75 \mathrm{~min}$, or the cumulative amount of moderate- and high-intensity activity was less than $150 \mathrm{~min}$ [8]; (8) fruit and vegetable intake was defined as insufficient if the daily average intake was <400 g [9]; (9) red meat intake was categorised as insufficient (daily average red meat intake $<18 \mathrm{~g}$ ), moderate $(18 \mathrm{~g} \leq$ to $<27 \mathrm{~g})$ or excessive $(\geq 27 \mathrm{~g})[10]$.

\subsection{Statistical Analysis}

SAS 9.4 software (SAS Institute Inc., Cary, NC, USA) was used to analyse the data. Continuous variables with normal distributions are presented as $\bar{x} \pm s$, and comparisons between groups were made using the $t$-test. Variables with skewed distributions are presented as the median with the 25th and 75th quantiles [M (P25, P75)], and comparisons between groups were made using the non-parametric statistical hypothesis test. Categorical variables are expressed as $\mathrm{N}(\%)$ and were compared by the chi-square test. The PROC SURVEYFREQ was used to calculate the standardised prevalence and $95 \% \mathrm{CI}$ of MetS and its components using the weight derived from the data published by the China National Bureau of Statistics in 2010. The influencing factors were analysed using a logistic regression model. A two-sided $p$ value $<0.05$ was considered to indicate statistical significance.

\section{Results}

\subsection{General Characteristics of the Participants}

A total of 130,018 participants were included $-61,775$ men $(47.5 \%)$ and 68,243 women $(52.5 \%)$. The average age of the men in the study was higher than that of the women. There were significant differences in MetS prevalence by sex, age, urban vs. rural residence, area of the country, education level, income, family history of hypertension, family history of diabetes, smoking status, alcohol consumption, physical activity, fruit and vegetable intake and red meat intake. Waist circumference, systolic blood pressure, diastolic blood pressure, triglycerides and FPG were significantly higher in men than in women, while BMI and high-density lipoprotein were significantly lower in men than in women $(p<0.05$, Table 1$)$.

\subsection{Standardised Prevalence of MetS and Its Components}

The standardised prevalence of MetS among Chinese residents aged 20 years or older was $31.1 \%$, with a significantly higher prevalence in women than in men ( $32.3 \%$ vs. $30.0 \%)$. The highest prevalence was found in participants aged $\geq 75$ years $(44.2 \%)$, and the lowest prevalence was found in participants aged $20-44$ years $(23.3 \%)$. The prevalence in the north $(35.9 \%)$ was higher than that in the south $(27.4 \%)$. There were significant differences in the prevalence of MetS among the groups of BMI, education level, family history of hypertension, family history of diabetes, physical activity, smoking, alcohol consumption and red meat intake $(p<0.05$, Table 2$)$. 
The standardised prevalences of high WC, high BP, elevated TG, low HDL-C and elevated FPG were 40.8\%, 49.4\%, 29.3\%, 41.1\% and 24.6\%, respectively. Among them, the standardised prevalences of high WC, high BP and low HDL-C were the highest (Figure 1). Among the 130,018 participants, 18,183 (14.0\%) had no abnormal components; $32,821(25.2 \%)$ had one abnormal component; 32,136 (24.7\%) had two abnormal components; 24,656 (19.0\%) had three abnormal components; 15,856 (12.2\%) had four abnormal components; and 6366 (4.9\%) had five abnormal components (Figure 2).

Table 1. Participant characteristics according to sex.

\begin{tabular}{|c|c|c|c|}
\hline & Men & Women & Total \\
\hline $\mathrm{N}$ & 61,775 & 68,243 & 130,018 \\
\hline Age, years * & $53.0(43.4,63.2)$ & $51.8(42.4,61.7)$ & $52.3(42.9,62.4)$ \\
\hline \multicolumn{4}{|l|}{ Residence location, $\mathrm{N}(\%)$ * } \\
\hline City & $25,371(41.1)$ & $29,878(43.8)$ & $55,249(42.5)$ \\
\hline Countryside & $36,404(58.9)$ & $38,365(56.2)$ & $74,769(57.5)$ \\
\hline \multicolumn{4}{|l|}{ Area of the country, N (\%)* } \\
\hline South & $31,232(50.6)$ & $35,253(51.7)$ & $66,485(51.1)$ \\
\hline North & $30,543(49.4)$ & $32,990(48.3)$ & $63,533(48.9)$ \\
\hline \multicolumn{4}{|l|}{ Education level, N (\%) * } \\
\hline Low & $24,315(39.4)$ & $36,645(53.7)$ & $60,960(46.9)$ \\
\hline Moderate & $22,516(36.5)$ & $18,608(27.3)$ & $41,124(31.6)$ \\
\hline High & $14,944(24.2)$ & $12,990(19.0)$ & $27,934(21.5)$ \\
\hline \multicolumn{4}{|l|}{ Income, $\mathrm{N}(\%) *$} \\
\hline Low & $17,612(28.5)$ & $18,535(27.2)$ & $36,147(27.8)$ \\
\hline Moderate & $15,524(25.1)$ & $17,265(25.3)$ & $32,789(25.2)$ \\
\hline High & $15,715(25.4)$ & $17,995(26.4)$ & $33,710(25.9)$ \\
\hline Very high & $12,924(20.9)$ & $14,448(21.2)$ & $27,372(21.1)$ \\
\hline Family history of hypertension, $\mathrm{N}(\%)$ * & $20,313(32.9)$ & $23,619(34.6)$ & $43,932(33.8)$ \\
\hline Family history of diabetes, N (\%) * & $5609(9.1)$ & $7149(10.5)$ & $12,758(9.8)$ \\
\hline \multicolumn{4}{|l|}{ Smoking, $\mathrm{N}(\%) *$} \\
\hline Never & $20,433(33.1)$ & $65,732(96.3)$ & $86,165(66.3)$ \\
\hline Former & $8673(14.0)$ & $569(0.8)$ & $9242(7.1)$ \\
\hline Current & $32,669(52.9)$ & $1942(2.9)$ & $34,611(26.6)$ \\
\hline \multicolumn{4}{|l|}{ Alcohol consumption, $\mathrm{N}(\%)$ * } \\
\hline Never & $21,429(34.7)$ & $51,799(75.9)$ & $73,228(56.3)$ \\
\hline Moderate & $28,415(46.0)$ & $15,377(22.5)$ & $43,792(33.7)$ \\
\hline Excessive & $11,931(19.3)$ & $1067(1.6)$ & $12,998(10.0)$ \\
\hline Physically active, $\mathrm{N}(\%)$ * & $41,112(66.6)$ & $50,741(74.4)$ & $91,853(70.7)$ \\
\hline $\begin{array}{l}\text { Insufficient fruit and vegetable intake, } \\
\qquad \mathrm{N}(\%)^{*}\end{array}$ & $32,012(51.8)$ & $34,970(51.2)$ & $66,982(51.5)$ \\
\hline \multicolumn{4}{|l|}{ Red meat intake, $\mathrm{N}(\%)^{*}$} \\
\hline Moderate & $4606(7.5)$ & $5714(8.4)$ & $10,320(7.9)$ \\
\hline Insufficient & $24,442(39.6)$ & $31,533(46.2)$ & $55,975(43.1)$ \\
\hline Excessive & $32,727(53.0)$ & $30,996(45.4)$ & $63,723(49.0)$ \\
\hline $\operatorname{BMI}\left(\mathrm{kg} / \mathrm{m}^{2}\right) *$ & $24.2(22.0,26.6)$ & $24.2(22.0,26.7)$ & $24.2(22.0,26.6)$ \\
\hline WC $(\mathrm{cm}) *$ & $85.3 \pm 10.0$ & $81.9 \pm 9.7$ & $83.5 \pm 10.0$ \\
\hline Systolic blood pressure $(\mathrm{mmHg}) *$ & $136.6 \pm 19.7$ & $134.4 \pm 22.2$ & $135.4 \pm 21.0$ \\
\hline Diastolic blood pressure $(\mathrm{mmHg})$ * & $81.7 \pm 11.4$ & $77.7 \pm 11.4$ & $79.6 \pm 11.5$ \\
\hline $\mathrm{TG}(\mathrm{mmol} / \mathrm{L}) *$ & $1.3(0.9,2.0)$ & $1.2(0.8,1.8)$ & $1.2(0.8,1.9)$ \\
\hline $\mathrm{HDL}-\mathrm{C}(\mathrm{mmol} / \mathrm{L}) *$ & $1.2 \pm 0.4$ & $1.3 \pm 0.3$ & $1.3 \pm 0.3$ \\
\hline Fasting plasma glucose $(\mathrm{mmol} / \mathrm{L})$ * & $5.2(4.8,5.7)$ & $5.2(4.8,5.6)$ & $5.2(4.8,5.7)$ \\
\hline
\end{tabular}

Data are presented as $\overline{\mathrm{x}} \pm \mathrm{s}$ for normal distributions, or as $\mathrm{M}(\mathrm{P} 25, \mathrm{P} 75)$ for skewed distributions, or $\mathrm{N} \mathrm{( \% )}$ ${ }^{*} p<0.05$ compared with men. Abbreviations: BMI, body mass index; WC, waist circumference; TG, triglycerides; HDL-C, high-density lipoprotein cholesterol. 
Table 2. Prevalence of metabolic syndrome in adults according to participant characteristics.

\begin{tabular}{|c|c|c|c|c|c|}
\hline & & Prevalence & $95 \% \mathrm{CI}$ & Rao-Scott $X^{2}$ & $p$-Value \\
\hline Total & & 31.1 & $30.0-32.2$ & & \\
\hline \multirow[t]{3}{*}{ Sex } & & & & 10.9707 & 0.0009 \\
\hline & Men & 30.0 & $28.8-31.3$ & & \\
\hline & Women & 32.3 & $30.9-33.6$ & & \\
\hline \multirow[t]{5}{*}{ Age, years } & & & & 1420.8214 & $<0.0001$ \\
\hline & $20-44$ & 23.3 & $22.1-24.5$ & & \\
\hline & $45-59$ & 39.0 & $37.9-40.1$ & & \\
\hline & $60-74$ & 43.9 & $42.4-45.5$ & & \\
\hline & $\geq 75$ & 44.2 & $41.3-47.2$ & & \\
\hline \multirow[t]{3}{*}{ Residence location } & & & & 2.8593 & 0.0908 \\
\hline & City & 32.0 & $30.2-33.8$ & & \\
\hline & Countryside & 30.1 & $28.8-31.4$ & & \\
\hline \multirow[t]{3}{*}{ Area of the country } & & & & 232.4353 & $<0.0001$ \\
\hline & South & 27.4 & $26.2-28.6$ & & \\
\hline & North & 35.9 & $34.7-37.2$ & & \\
\hline \multirow[t]{4}{*}{ BMI } & & & & $54,564.5498$ & $<0.0001$ \\
\hline & Normal & 11.8 & $11.1-12.6$ & & \\
\hline & Overweight & 41.0 & $39.9-42.0$ & & \\
\hline & Obese & 70.5 & $69.0-72.0$ & & \\
\hline \multirow[t]{4}{*}{ Education level } & & & & 59.5475 & $<0.0001$ \\
\hline & Low & 35.8 & $34.4-37.2$ & & \\
\hline & Moderate & 30.3 & $29.0-31.6$ & & \\
\hline & High & 27.1 & $24.9-29.3$ & & \\
\hline \multirow[t]{5}{*}{ Income } & & & & 1.5158 & 0.6786 \\
\hline & Low & 30.9 & $29.5-32.4$ & & \\
\hline & Moderate & 30.4 & $29.2-31.6$ & & \\
\hline & High & 31.7 & $30.4-33.1$ & & \\
\hline & Very high & 31.4 & $28.7-34.1$ & & \\
\hline \multirow[t]{3}{*}{$\begin{array}{l}\text { Family history of } \\
\text { hypertension }\end{array}$} & & & & 87.8033 & $<0.0001$ \\
\hline & No & 29.0 & $28.0-30.0$ & & \\
\hline & Yes & 34.8 & $33.1-36.4$ & & \\
\hline \multirow[t]{3}{*}{$\begin{array}{l}\text { Family history of } \\
\text { diabetes }\end{array}$} & & & & 107.2048 & $<0.0001$ \\
\hline & No & 30.0 & $28.9-31.0$ & & \\
\hline & Yes & 39.9 & $37.5-42.3$ & & \\
\hline \multirow[t]{3}{*}{ Physical activity } & & & & 6.7119 & 0.0096 \\
\hline & Not active & 32.1 & $30.7-33.5$ & & \\
\hline & Active & 30.6 & $29.5-31.8$ & & \\
\hline \multirow[t]{4}{*}{ Smoking status } & & & & 34.7917 & $<0.0001$ \\
\hline & Never & 31.2 & $30.0-32.5$ & & \\
\hline & Former & 37.7 & $35.4-40.0$ & & \\
\hline & Current & 29.6 & $28.1-31.0$ & & \\
\hline \multirow[t]{4}{*}{$\begin{array}{c}\text { Alcohol } \\
\text { consumption }\end{array}$} & & & & 40.8781 & $<0.0001$ \\
\hline & Never & 32.6 & $31.6-33.7$ & & \\
\hline & Moderate & 28.7 & $27.2-30.2$ & & \\
\hline & Excessive & 33.2 & $30.9-35.5$ & & \\
\hline \multirow[t]{3}{*}{$\begin{array}{l}\text { Fruit and vegetable } \\
\text { intake }\end{array}$} & & & & 2.3882 & 0.1223 \\
\hline & Sufficient & 31.6 & $30.5-32.7$ & & \\
\hline & Insufficient & 30.6 & $29.2-32.0$ & & \\
\hline \multirow[t]{4}{*}{ Red meat intake } & & & & 36.6381 & $<0.0001$ \\
\hline & Moderate & 30.8 & $29.0-32.5$ & & \\
\hline & Insufficient & 32.8 & $31.5-34.1$ & & \\
\hline & Excessive & 29.8 & $28.6-31.0$ & & \\
\hline
\end{tabular}




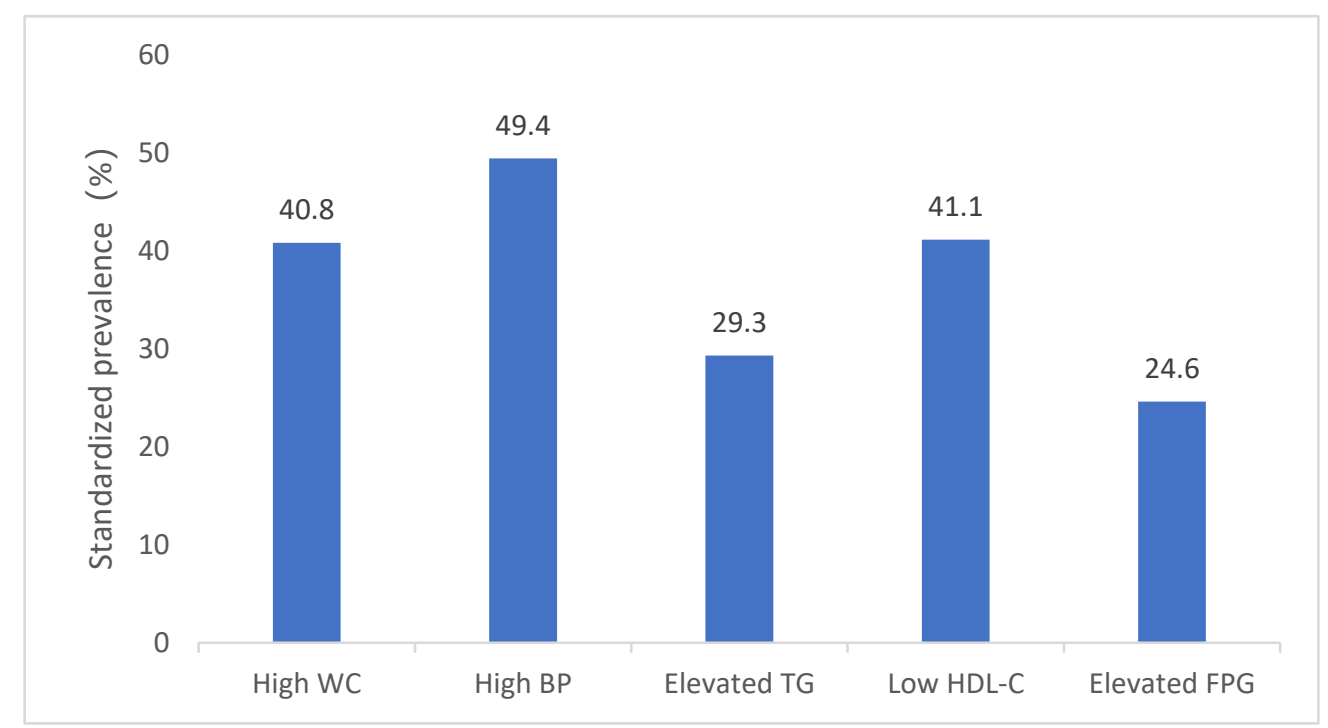

Figure 1. Standardised prevalence of metabolic components among adults in China. WC, waist circumference; BP, blood pressure; TG, triglycerides; HDL-C, high-density lipoprotein cholesterol; FPG, fasting plasma glucose.

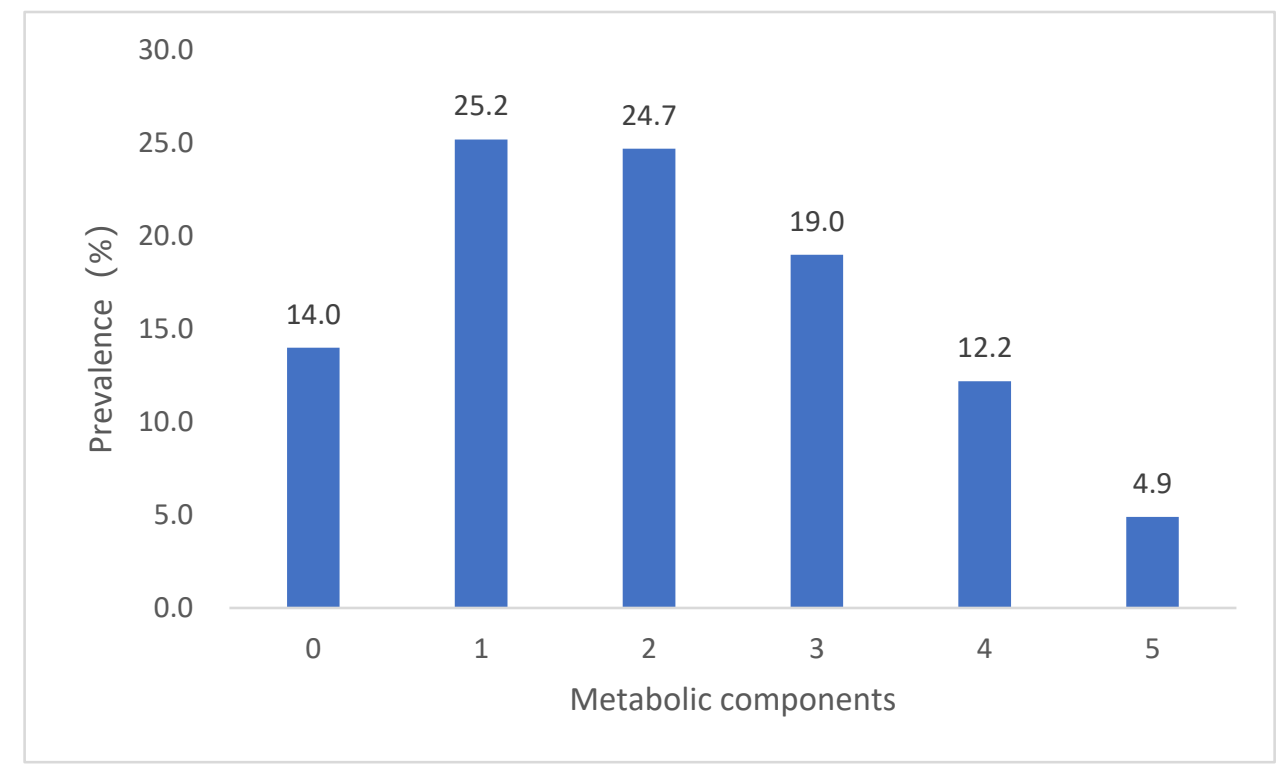

Figure 2. Metabolic components among adults in China.

\subsection{Multivariate Logistic Regression}

Variables with statistical significance in the univariate analysis and those that were not significant but are closely related to MetS according to medical theory were included in the multivariate logistic regression. A stepwise regression method was adopted, and the variables that were finally included in the model were sex, age, location of residence, area of the country, BMI, education level, income, family history of hypertension, family history of diabetes, physical activity, smoking status, alcohol consumption, fruit and vegetable intake, and red meat intake.

The prevalence of MetS was higher in women than in men $(\mathrm{OR}=1.773,95 \%$ $\mathrm{CI}=1.709-1.840)$. Every 1 year increase in age was associated with a $3.7 \%(95 \% \mathrm{CI}=3.6 \%-3.9 \%)$ increase in the prevalence of MetS. The following factors were associated with a higher prevalence of MetS: living in northern China ( $\mathrm{OR}=1.087,95 \% \mathrm{CI}=1.058-1.117)$, high BMI $(\mathrm{OR}=1.402,95 \% \mathrm{CI}=1.395-1.408)$, higher income [OR (95\% CI): 1.044 (1.007-1.083), 
1.083 (1.044-1.124), and 1.123 (1.078-1.170) for moderate, high, and very high income, respectively], family history of hypertension $(\mathrm{OR}=1.237,95 \% \mathrm{CI}=1.203-1.273)$, family history of diabetes $(\mathrm{OR}=1.491,95 \% \mathrm{CI}=1.426-1.558)$ and current smoking $(\mathrm{OR}=1.143$, $95 \% \mathrm{CI}=1.098-1.191)$. Living in the countryside $(\mathrm{OR}=0.960,95 \% \mathrm{CI}=0.932-0.988)$, moderate alcohol consumption $(\mathrm{OR}=0.917,95 \% \mathrm{CI}=0.889-0.946)$ and being physically active $(\mathrm{OR}=0.887,95 \% \mathrm{CI}=0.862-0.913)$ were associated with a lower prevalence of MetS (Table 3).

Table 3. Logistic regression analysis results of influencing factors.

\begin{tabular}{|c|c|c|c|c|c|c|c|}
\hline Influencing Factor & & $\beta$ & SE & Wald $X^{2}$ & $p$ & OR & $95 \% \mathrm{CI}$ \\
\hline Intercept & & -12.4553 & 0.0961 & $16,784.5555$ & $<0.0001$ & & \\
\hline Sex & Women vs. Men & 0.5727 & 0.0189 & 918.6448 & $<0.0001$ & 1.773 & $1.709-1.840$ \\
\hline Age & & 0.0368 & 0.0005 & 4751.4066 & $<0.0001$ & 1.037 & $1.036-1.039$ \\
\hline Residence location & Countryside vs. City & -0.0411 & 0.0148 & 7.7242 & 0.0054 & 0.960 & $0.932-0.988$ \\
\hline Area of the country & North vs. South & 0.0835 & 0.0136 & 37.4822 & $<0.0001$ & 1.087 & $1.058-1.117$ \\
\hline BMI & & 0.3377 & 0.0024 & $19,715.8134$ & $<0.0001$ & 1.402 & $1.395-1.408$ \\
\hline \multirow[t]{3}{*}{ Income } & Moderate vs. Low & 0.0433 & 0.0188 & 5.3170 & 0.0211 & 1.044 & $1.007-1.083$ \\
\hline & High vs. Low & 0.0800 & 0.0190 & 17.6248 & $<0.0001$ & 1.083 & $1.044-1.124$ \\
\hline & Very high vs. Low & 0.1160 & 0.0208 & 30.9902 & $<0.0001$ & 1.123 & $1.078-1.170$ \\
\hline Family history of hypertension & Yes vs. No & 0.2130 & 0.0146 & 212.8383 & $<0.0001$ & 1.237 & $1.203-1.273$ \\
\hline Family history of diabetes & Yes vs. No & 0.3992 & 0.0225 & 315.9245 & $<0.0001$ & 1.491 & $1.426-1.558$ \\
\hline \multirow[t]{2}{*}{ Smoking status } & Former vs. Never & 0.0289 & 0.0292 & 0.9808 & 0.3220 & 1.029 & $0.972-1.090$ \\
\hline & Current vs. Never & 0.1339 & 0.0207 & 41.6962 & $<0.0001$ & 1.143 & $1.098-1.191$ \\
\hline \multirow[t]{2}{*}{ Alcohol consumption } & Moderate vs. Never & -0.0868 & 0.0160 & 29.6303 & $<0.0001$ & 0.917 & $0.889-0.946$ \\
\hline & Excessive vs. Never & 0.0001 & 0.0254 & 0.0000 & 0.9957 & 1.000 & $0.952-1.051$ \\
\hline Physical activity & Active vs. Not active & -0.1197 & 0.0149 & 64.7071 & $<0.0001$ & 0.887 & $0.862-0.913$ \\
\hline
\end{tabular}

Abbreviations: BMI, body mass index; CI, confidence interval; OR, odds ratio; SE, standard error.

\section{Discussion}

Based on data from China Nutrition and Health Surveillance (2015-2017), this analysis provides up-to-date information on the prevalence of and risk factors for MetS in Chinese adults. We found that the standardised prevalence of MetS was $31.1 \%$. There was a significantly higher prevalence in women than in men $(32.3 \%$ vs. $30.0 \%, p<0.001)$ and in those living in northern China vs. southern China (35.9\% vs. $27.4 \%, p<0.001)$. The standardised prevalences of high WC, high BP and low HDL-C were $40.8 \%, 49.4 \%$ and $41.1 \%$, respectively. These three variables are important components of MetS and should be addressed as key factors for MetS prevention and treatment. Only $14.0 \%$ of adults had no abnormal MetS components; thus, greater than $4 / 5$ of adults had at least one abnormal MetS component.

Understanding which factors are associated with a high MetS rate would help to identify individuals who are at a greater risk of MetS. Consistent with previous studies, we found that the prevalence of MetS among Chinese adults was related to one's socioeconomic status and lifestyle factors. Sex, age, location of residence (city or countryside), area of the country (north or south), BMI, income, family history of hypertension, family history of diabetes, smoking status, alcohol consumption and physical activity were related to MetS prevalence. There was a higher prevalence of MetS in women than in men; this trend has also been observed in Porto (24.9\% vs. $17.4 \%$ ) [11], Iran (47.1\% vs. $36.5 \%$ ) [12] and China $(15.57 \%$ vs. $12.31 \%)$ [13]. Postmenopausal status is associated with an increased risk of central obesity and insulin resistance [14], which may be the cause of the sex differences seen in MetS prevalence; however, further research is required to verify this. The MetS prevalence tended to increase with increasing age, which was similar to the findings of Wang et al. [15]. Living in the countryside was associated with a lower prevalence of MetS than living in a city, which was similar to the findings of Xi et al. [16], while living in northern China was associated with a higher prevalence of MetS than living in southern China, which was also observed by Gu et al. [4]. The BMI is an important measure of 
obesity and overall health and is closely related to MetS $[17,18]$. This study found that every 1 unit increase in BMI was associated with a $40.2 \%$ increase in the prevalence of MetS. No association was found between education level and MetS prevalence, which was consistent with the findings of Park et al. [19]. Participants with higher incomes were more likely to have MetS than those with a low income, which may be related to the influence of economic development on diet structure and health awareness. Prasad et al. found that a middle-to-high socioeconomic status significantly contributed to an increased risk of MetS [20]. A family history of diabetes or hypertension was also significantly related to the prevalence of MetS. Carmelli et al. found that the consistency rates of diabetes, hypertension and obesity in identical twins were significantly higher than those in fraternal twins, indicating that genetic factors have an important relationship with the occurrence of MetS [21]. Current smoking status was a risk factor for MetS, which was consistent with previous studies $[22,23]$. Compared with never consumed alcohol, moderate alcohol consumption led to a lower risk of developing MetS, and this was consistent with the findings of Tresserra-Rimbau [24]. Being physically active was associated with a lower prevalence of MetS, which was also consistent with recent research showing that exercise can reduce the incidence of MetS $[25,26]$. Studies have confirmed that red meat intake is positively correlated with MetS occurrence $[27,28]$, while eating more fruits and vegetables is protective against MetS [29,30]. This study did not identify any correlations between diet and the risk of MetS. This lack of correlation may have been related to bias. Furthermore, individuals who had previously developed MetS or a component of MetS may have changed their diet.

The survey data are representative of the whole country. After weighted adjustment, this study well reflects the epidemic characteristics of MetS among residents aged 20 years and older in China. However, this study also has some limitations. First, this was a cross-sectional study; thus, causal relationships could not be determined. Second, the investigation of alcohol consumption was limited to individuals' consumption patterns within the previous 12 months; therefore, alcohol consumption may have been underestimated.

\section{Conclusions}

We found that the prevalence of MetS among residents aged 20 years or older in China is increasing, especially among women, those aged 45 years or older and urban residents. Preventive efforts, such as quitting smoking and engaging in physical activity, are recommended to reduce the risk of MetS.

Author Contributions: Conceptualization, D.Y. and X.L.; methodology, F.Y., Y.B., D.Y. and X.L.; formal analysis, F.Y. and D.Y.; investigation, L.Z.; resources, L.Z.; data curation, Y.L., L.J., H.F. and W.P.; writing—original draft preparation, F.Y., Y.B. and D.Y.; writing—review and editing, Y.B., H.F., W.P., D.Y. and X.L.; project administration, L.Z. All authors have read and agreed to the published version of the manuscript.

Funding: National Key Research and Development Project (Number: 2018YFC1603103); National Health Commission of the People's Republic of China Medical Reform Major Program: China National Chronic Diseases and Nutrition Surveillance of Adults (2015-2017).

Institutional Review Board Statement: The study was conducted according to the guidelines of the Declaration of Helsinki and was approved by the Ethics Committee of the National Institute for Nutrition and Health, Chinese Center for Disease Control and Prevention (Approval number: 201519-A and 201614).

Informed Consent Statement: Any Informed consent was obtained from all subjects involved in the study.

Data Availability Statement: The data is not allowed to be disclosed according to the National Institute for Nutrition and Health, Chinese Center for Disease Control and Prevention.

Acknowledgments: We thank all the participants who took part in the China Nutrition and Health Surveillance (2015-2017) and the staff who conducted this study. 
Conflicts of Interest: No conflict of interest were declared.

\section{References}

1. Ozmen, M.; Yersal, O.; Ozturk, S.; Solmaz, D.; Koseeoglu, M.H. Prevalence of the metabolic syndrome in rheumatoid arthritis. Eur. J. Rheumatol. 2014, 1, 1-4. [CrossRef]

2. $\quad$ Lim, S.; Shin, H.; Song, J.H.; Kwak, S.H.; Kang, S.M.; Won, Y.J.; Choi, S.H.; Cho, S.I.; Park, K.S.; Lee, H.K.; et al. Increasing prevalence of metabolic syndrome in Korea: The Korean National Health and Nutrition Examination Survey for $1998-2007$. Diabetes Care 2011, 34, 1323-1328. [CrossRef]

3. Aguilar, M.; Bhuket, T.; Torres, S.; Liu, B.; Wong, R.J. Prevalence of the metabolic syndrome in the United States, 2003-2012. JAMA 2015, 313, 1973-1974. [CrossRef] [PubMed]

4. $\quad \mathrm{Gu}, \mathrm{D} . ;$ Reynolds, K.; Wu, X.; Chen, J.; Duan, X.; Reynolds, R.F.; Whelton, P.K.; He, J.; For, T.I.C.G.; InterASIA, C.G. Prevalence of the metabolic syndrome and overweight among adults in China. Lancet 2005, 365, 1398-1405. [CrossRef]

5. Li, Y.; Zhao, L.; Yu, D.; Wang, Z.; Ding, G. Metabolic syndrome prevalence and its risk factors among adults in China: A nationally representative cross-sectional study. PLoS ONE 2018, 13, e199293. [CrossRef]

6. Yu, D.; Zhao, L.; Zhang, J.; Yang, Z.; Ding, G. China Nutrition and Health Surveys (19822017). China CDC Wkly. 2021, 3, 193-195. [CrossRef]

7. Grundy, S.M.; Cleeman, J.I.; Daniels, S.R.; Donato, K.A.; Eckel, R.H.; Franklin, B.A.; Gordon, D.J.; Krauss, R.M.; Savage, P.J.; Smith, S.C.; et al. Diagnosis and Management of the Metabolic Syndrome. Circulation 2005, 112, 2735-2752. [CrossRef] [PubMed]

8. World Health Organization. WHO Guidelines on Physical Activity and Sedentary Behaviour; World Health Organization: Geneva, Switzerland, 2020.

9. World Health Organization. Draft Action Plan for the Prevention and Control of Noncommunicable Diseases 2013-2020; IChemE: Rugby, UK, 2013.

10. Afshin, A.; Sur, P.J.; Fay, K.A.; Cornaby, L.; Ferrara, G.; Salama, J.S.; Mullany, E.C.; Abate, K.H.; Abbafati, C.; Abebe, Z.; et al. Health effects of dietary risks in 195 countries, 1990-2017: A systematic analysis for the Global Burden of Disease Study 2017. Lancet 2019, 393, 1958-1972. [CrossRef]

11. Santos, A.C.; Ebrahim, S.; Barros, H. Gender, socio-economic status and metabolic syndrome in middle-aged and old adults. BMC Public Health 2008, 8, 62. [CrossRef]

12. Hajian-Tilaki, K.; Heidari, B.; Firouzjahi, A.; Bagherzadeh, M.; Hajian-Tilaki, A.; Halalkhor, S. Prevalence of metabolic syndrome and the association with socio-demographic characteristics and physical activity in urban population of Iranian adults: A population-based study. Diabetes Metab. Syndr. Clin. Res. Rev. 2014, 8, 170-176. [CrossRef]

13. Xu, T.; Zhu, G.; Han, S. Prevalence of and lifestyle factors associated with metabolic syndrome determined using multi-level models in Chinese adults from a cross-sectional survey. Medicine 2020, 99, e22883. [CrossRef]

14. Fujimoto, W.Y.; Bergstrom, R.W.; Boyko, E.J.; Chen, K.; Kahn, S.E.; Leonetti, D.L.; McNeely, M.J.; Newell, L.L.; Shofer, J.B.; Wahl, P.W. Type 2 diabetes and the metabolic syndrome in Japanese Americans. Diabetes Res. Clin. Pract. 2000, 50, S73-S76. [CrossRef]

15. Wang, G.; Li, L.; Pan, Y.; Tian, G.; Lin, W.; Li, Z.; Chen, Z.; Gong, Y.; Kikano, G.E.; Stange, K.C.; et al. Prevalence of metabolic syndrome among urban community residents in China. BMC Public Health 2013, 13, 599. [CrossRef]

16. Xi, B.; He, D.; Hu, Y.; Zhou, D. Prevalence of metabolic syndrome and its influencing factors among the Chinese adults: The China Health and Nutrition Survey in 2009. Prev. Med. 2013, 57, 867-871. [CrossRef]

17. Zhou, W.; Li, C.L.; Cao, J.; Feng, J. Metabolic syndrome prevalence in patients with obstructive sleep apnea syndrome and chronic obstructive pulmonary disease: Relationship with systemic inflammation. Clin. Respir. J. 2020, 14, 1159-1165. [CrossRef]

18. Hannoun, Z.; Harraqui, K.; Ben, A.R.; Tahiri, K.; Smail, O.B.; Samara, I.; Arabi, F.E.; Bour, A. Epidemiological profile and clinical characteristics of metabolic syndrome in Marrakesh, Morocco. Pan Afr. Med. J. 2020, 36, 133. [CrossRef]

19. Park, H.S. The metabolic syndrome and associated lifestyle factors among South Korean adults. Int. J. Epidemiol. 2004, 33, 328-336. [CrossRef]

20. Prasad, D.S.; Kabir, Z.; Dash, A.K.; Das, B.C. Prevalence and risk factors for metabolic syndrome in Asian Indians: A community study from urban Eastern India. J. Cardiovasc. Dis. Res. 2012, 3, 204-211. [CrossRef]

21. Carmelli, D.; Cardon, L.R.; Fabsitz, R. Clustering of hypertension, diabetes, and obesity in adult male twins: Same genes or same environments? Am. J. Hum. Genet. 1994, 55, 566-573.

22. Yu, M.; Xu, C.; Zhu, H.; Hu, R.; Zhang, J.; Wang, H.; He, Q.; Su, D.; Zhao, M.; Wang, L.; et al. Associations of Cigarette Smoking and Alcohol Consumption with Metabolic Syndrome in a Male Chinese Population: A Cross-Sectional Study. J. Epidemiol. 2014, 24, 361-369. [CrossRef]

23. Jeong, J.; Yu, J. Prevalence and Influencing Factors of Metabolic Syndrome among Persons with Physical Disabilities. Asian Nurs. Res. 2018, 12, 50-55. [CrossRef] [PubMed]

24. Tresserra-Rimbau, A.; Medina-Remón, A.; Lamuela-Raventós, R.M.; Bulló, M.; Salas-Salvadó, J.; Corella, D.; Fitó, M.; Gea, A.; Gómez-Gracia, E.; Lapetra, J. Moderate red wine consumption is associated with a lower prevalence of the metabolic syndrome in the PREDIMED population. Br. J. Nutr. 2015, 113, S121-S130. [CrossRef] [PubMed]

25. Lee, J.; Kim, Y.; Jeon, J.Y. Association between physical activity and the prevalence of metabolic syndrome: From the Korean National Health and Nutrition Examination Survey, 1999-2012. SpringerPlus 2016, 5, 1870. [CrossRef] 
26. Houti, L.; Hamani-Medjaoui, I.; Lardjam-Hetraf, S.A.; Ouhaibi-Djellouli, H.; Chougrani, S.; Goumidi, L.; Mediene-Benchekor, S. Prevalence of Metabolic Syndrome and its Related Risk Factors in the City of Oran, Algeria: The ISOR Study. Ethn. Dis. 2016, 26, 99-106. [CrossRef] [PubMed]

27. Huang, L.N.; Wang, H.J.; Wang, Z.H.; Zhang, J.G.; Jia, X.F.; Zhang, B.; Ding, G.Q. Association of Red Meat Usual Intake with Serum Ferritin and the Risk of Metabolic Syndrome in Chinese Adults: A Longitudinal Study from the China Health and Nutrition Survey. Biomed. Environ. Sci. 2020, 33, 19-29. [CrossRef]

28. Shang, X.; Scott, D.; Hodge, A.; English, D.R.; Giles, G.G.; Ebeling, P.R.; Sanders, K.M. Dietary protein from different food sources, incident metabolic syndrome and changes in its components: An 11-year longitudinal study in healthy community-dwelling adults. Clin. Nutr. 2017, 36, 1540-1548. [CrossRef]

29. Esmaillzadeh, A.; Kimiagar, M.; Mehrabi, Y.; Azadbakht, L.; Hu, F.B.; Willett, W.C. Fruit and vegetable intakes, C-reactive protein, and the metabolic syndrome. Am. J. Clin. Nutr. 2006, 84, 1489-1497. [CrossRef]

30. Tian, Y.; Su, L.; Wang, J.; Duan, X.; Jiang, X. Fruit and vegetable consumption and risk of the metabolic syndrome: A meta-analysis. Public Health Nutr. 2018, 21, 756-765. [CrossRef] 